NBER WORKING PAPER SERIES

PLANT CLOSINGS, LABOR DEMAND

AND THE VALUE OF THE FIRM

Daniel S. Hamermesh

Working Paper No. 1839

NATIONAL BUREAU OF ECONOMIC RESEARCH 1050 Massachusetts Avenue

Cambridge, MA 02138

February 1986

Professor of Economics, Michigan State University, and research associate, National Bureau of Economic Research. Work on this project was funded by the National Science Foundation, grant SES-8408206. Helpful comments were provided by Harry Holzer, Steven Matusz, participants in the NBER Summer Institute and in seminars at several universities, and especially by Jack Meyer. Francis Cheung provided programming and research assistance of a truly extraordinary caliber. The research reported here is part of the NBER's research program in Labor Studies. Any opinions expressed are those of the author and not those of the National Bureau of Economic Research. 
NBER Working Paper \#1839

February 1986

\section{Plant Closings, Labor Demand and the Value of the Firm}

\section{ABSTRACT}

This study postulates an internal labor market in which workers accumulate firmspecific human capital that raises the value of the firm and insulates it to some extent from the vagaries of product demand that might result in its closing. Negative productmarket shocks reduce wage growth and increase the probability of the firm closing. The model also predicts a U-shaped relation between the probability of the plant closing and the length of a worker's tenure, a proxy for firm-specific human investment. PSID data for 1977 through 1981 are used to produce welghted-probit estimates of the parameters of an equation describing the probability of displacement. The results support most of the predictions of the model, but similarly specified equations describing the probability of permanent layoff indicate that a theory of plant closings must differ from that of layoffs. The parameter estimates are used to infer an analogue to the firm's elasticity of demand for labor and to deduce the wage reduction necessary to avoid an increase in the probability of a plant closing when a negative demand shock occurs.

Daniel S. Hamermesh Department of Economics Michigan State University East Lansing, MI 48824

(517) $332-3448$ 
More Workers Resist Employers' Demands for Pay Concessions. Unions Say Fast Givebacks Haven't Saved Any Jobs, See a Ploy to Trim Wages; but Firms Do Close Plants. 1

\section{Introduction}

With the introduction of the notion of implicit contracts between workers and employers by Azariadis (1975) and Baily (1974) there has come a host of variants on the basic theme of long-term employment relationships. SSee Rosen, 1985, for a survey of many of these.) This burgeoning of theoretical work has not been matched, however, by a growth in the use of the basic concept to study empirical aspects of labor-market behavior in new ways. Other than a few studies (e.9., Lazear, 1979, and Raisian, 1983) that have used the theory to motivate specific empirical results, its main application has been to make economists more aware of the importance of long-term employment relations in labor markets.

In this study a contracting approach is used to examine the relationships between firms whose own survival is uncertain and their workers. Workers are viewed as contracting with their employers for a package that includes a probability that the job will exist and an increment in wages above the entry-level wage. They are considered tied to the employer by a wedge between the ir wage in the firm and the wage tlog could obtain elsewhere. Using standard assumptions about workers risk aversion, and a somewhat novel way u? specifying employers profit functions, I analyze the nature of equilibrium combinations of observed risks (of the job disappearing) and changes in returns to these tenured workers. In addition to examining this relationship the study provides information on what happens to firms before they close, and thus implicitly gives evidence on the dynamics of declining industries. 
The empirical estimates provide a way of inferring parameters descriting employment relations that could not otherwise be measured, or could not be

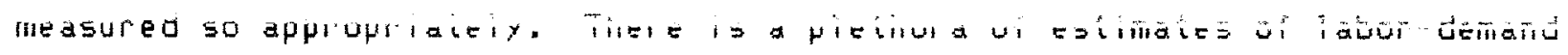
elasticities, but very few are based on microeconomic data. As Hamermesh $(1986)$ shows, the use of aggregated data on both the price and quantity of labor induces an inherent simultaneity in these estimates. By inferring elasticities from microeconomic data, this study may provide more precision than has heretofore been possible. The model also allows one to infer the size of wage concessions that workers must offer to keep plants from closing. since plant closings and concessionary wage bargaining have received increasing attention in the U.S. and rewhere in the past decade, this additional focus can provide a guide to the relationship between these two phenomena. ${ }^{2}$

\section{I. Contracting and the Risk of Displacement}

In this Section I derive the equilibrium relationship between the wage rate received by homogeneous workers and the probability that their jobs will disappear because their employer closes the business. When workers sort themselves among firms, one of the risks they consider is that the job will disappear due to exogenous negative shocks. As with any other such risk, we may assume that the combination of workers' risk aversion and employers' production technologies results in a positive relationship between the observed probability that a plant will close and the wage rate. ${ }^{3}$ Workers thus enter firms at a reservation wage $W^{r}$ that makes them indifferent between choosing between that firm and at least one other. The market produces a compensating differential in the reservation wage at different firms that is positively related to the ex ante expected probability that the firm will 
close. This reservation wage, including the comperisating differential for the firm-specific expected risk of closing, is the basis against which workers compare the wages they receive once they have joined the firm.

Workers who enter the firm acquire firm-specific human capital that raises their wage rates above what they could obtain elsewhere, other things, including the expected risk of displacement, equal. Assume for the moment that such training is instantaneous, so that all workers who have joined the firm are identical. I assume that the firm employing such workers faces a known distribution of random prices $P, h(P, S)$, where $P \geq 0$ and $S$ is an index of demand. S may be viewed as an exogenous demand shock to markets in which the firm sells, with a higher s shifting the distribution of prices to the right iso that $S \mathrm{can}$ be viewed as a positive shock to the market in which the firm sells). I assume the capital stock is fixed at $K *$ and write the firm's profits as:

$\pi=P X-W L-r K *$,

where production is characterized by $X=F(L, K *), W$ is the wage rate, and $r$ is the cost of capital services.

I assume that wages are set by the firm and its workers at the start of each time period in full knowledge of the state of product-market shocks, as indexed by a particular value of 5 , say $5^{*}$. The firm then draws from the distribution $h_{\left(P, S^{*}\right)}$ and decides whether or not to shut down. Let $\pi^{*}$ be the critical level of profits that determines the firm's continued existence. Above this level the firm will stay in business; below it, the firm will close. Then at this level of profits the product price must be:

(1) $P_{*}^{*}=[\pi *+W L+r K *] / X$. 
This means that the probability the firm will close, $p$, is:

$$
n=\int_{u}^{P^{*}} h(P, S) d P
$$

Equation (2) implicitly defines a relationship between $p$ and $w$ for a given set of exogenous conditions determining $S$. This relationship can be viewed as the set of probabilities that the firm remains in business consistent with each particular wage rate at a given $5^{*}$. The probability depends on the distribution of stochastic prices, a distribution that is shifted by changes in $S$. The slope of the relationship is:

(3) $(d p / d W)_{S=S *}=h(P *, S * d P * / d N$,

where:

$d P * / d W=[[W-P * F L L L / \delta W+L] / X$.

Now $d P * / d k$ can be rewritten as:

(4) $d P * / d W=\left[1+\eta-\eta F_{L} P * / W\right][L / X]$

where $\eta$ is the total demand elasticity for labor. So long as workers are not paid in excess of their marginal revenue products, we can be sure from ( 3 ) that $\mathrm{dF}^{*} / \mathrm{dW}>0$, and thus that $\left(\mathrm{dp} / \mathrm{dW}_{S=S *}>0\right.$. The probabilistic shut-down frontier for $S=S *$ is shown in Figure 1 . It shows the set of all points along which probabilistic profits are at the competitive minimum given values of and the state of the market 5 . Viewed differently, it shows the probability of plant closing at each wage. Favorable shocks shift the frontier to the right, unfavorable ones to the left. In order to present both sides of the internal labor market, the frontier is drawn with $w^{r}$ as the origin.)

The typical person attached to the firm is assumed to choose between a higher wage and a reduced risk that the firm will close. Hours of work are assumed constant: workers simply choose among varying combinations of a wage 


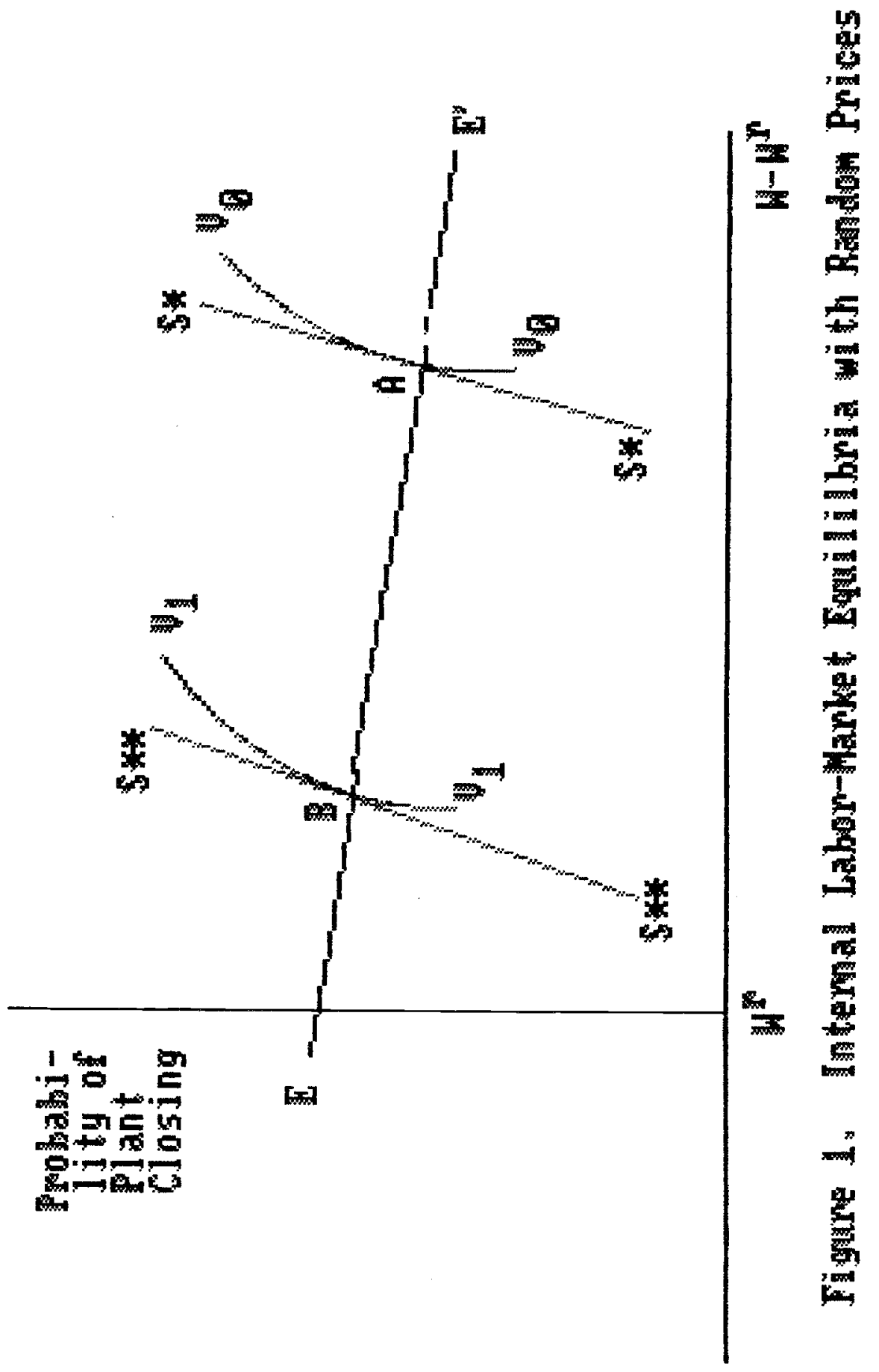


and an uncertain probability of the job disappearing because the plant

closes. I define workers expected utility once they have taken a job with a particular firm and acquired firm-specific training in terms of the excess W-ur over what they could obtain outside the firm. The typical worker's expected utility increment from remaining in the firm is thus:

(5) $U=[1-p] U\left(W-w^{\Gamma}\right)+p U(0), U^{\prime}>0, U^{\prime \prime}<0$.

Obviously, if $W$ falls below what can be obtained elsewhere, the worker will leave the firm voluntarily. We are thus implicitly examining changes in wand p only within some limited range. Beyond that range the worker will break the contract with the employer.

Scaling $U$ so that $U(0)=0$ and setting the total differential of (5) equal to zeroyield:

(6) $(d p / d W)_{U=U *}=[1-p] U^{\prime} / U>0$.

Because of the assumptions about $U$ the indifference map between $p$ and $W$ contains curves that are concave to the origin. ${ }^{4}$ Typical indifference curves $U_{0}$ and $V_{1}$ are shown in Figure 1. Combinations of wage rates and risks of plant closing along $U_{0}$ are preferred to those along $V_{1}$, for at each wage rate along the former the risk of losing the job is lower.

Equilibrium in the internal labor market is defined by the tangency of the indifference curve to the probabilistic shut-down frontier for fixed $s *$, i.e., where:

(7) $(d p / d W)_{S=5 *}=(d p / d W)_{y=V_{*}}$.

The presence of firm-specific investment insulates the average worker to some extent from random shocks to product demand; for that reason the equilibrium 
is drawn for the average set of exogerious conditions, $S_{*}$, at point $A$ in the first quadrant of Figure 1. A shock to this equilibrium, for example, a migative shock that lowers $S$ to $5 * *$ such that the probability mass of $h$ is shifted to the left, produces a new equilibrium on the new shut-down frontier S**S** in Figure 1. Without specific assumptions about the shape of the zero-profit frontier, one cannot define the slope of EE', the locus of equilibrium combinations $(p, w)$. However, as $I$ show in the next section, under very reasonable assumptions the locum the negative slope shown in Figure 1.

The discussion has dealt with the contractual relationship between a worker and an employer in a firm whose continued existerse is uncertain. It deals with a distinctly nonmarginal event--the demise of a plant or firm. It is designed to explain, using the mechanism of a minimum required rate of profit and workers' attitudes toward risk, why some plants or firms shut down rather than make marginal changes that, with a neoclassical technology ard individualized setting of wages, would allow the plant or firm to continue in paistence.

The analysis applies to the discussion of plant closings and not to permanent layoffs from continuing enterprises. "wile the employers' side could be applied mutatis mutandis to analyze layoffs, changing the worker's side appropriately would require specifying a utility map that includes both workers beliefs about their own probabilities of being subject to layoff should $S$ decrease and a mechanism for ordering layoffs. See Wright, 1985, for an analysis that embodies such a mechanism.) Without these changes the model as presented in this section is not likely to go far in explaining layoff behavior.

\section{Estimating Equations and Data}


To move from the set of equilibrium points defined by (7) under various values of $s$ to an equation that allows inferences to be drawn about the shape of the locus of equilibria one needs to specify the forms of the utility and production functions. In the case of the former, let:

$$
\left.U=[w-w]^{\Gamma}\right]^{1-\varepsilon} /[1-\varepsilon], \delta<1,
$$

a standard form, where $s$ is a measure of relative risk aversion. Then from (6):

(8) $(d p / d W)_{V=V_{*}}=[1-p][1-\varepsilon] / \delta\left(w-W^{2}\right]$.

On the firm's side, very little can be concluded about the convexity or concavity of the zero-profit frontier without making very restrictive assumptions about the density function h(P,S). Being unwilling to make these assumptions about the distribution of prices, 1 instead assume a linear approximation to (3) and let:

(9) $(d p / d N)_{S=S *}=\gamma$.

Throughout the discussion thus far I have assumed labor is homogeneous in production when it sinters the firm and is then instantaneously trained. This assumption ignores the likelihood that the shared investment in firm-specific human capital that generates a wedge between workers' productivity and their wage is made over a long period of time. Assume, therefore, that effective units of labor, L', are related to nominal units, $L$, by:

$$
L^{\prime}=L G(T N) \text {, where G(TN) } \geq 1, G^{\circ}>0, G^{\prime \prime}<0 \text {, }
$$

following the evidence that the amount of firm-specific human capital embodied in workers increases at a decreasing rate with their tenure, TN, in the firm 
(e.9. Mincer-Jovanouic, 1981). The training adds more to workers"

productivity than it does to their wages, and the difference widens over much of the range of TN. Then the slope in ( 3 ) and (4) can be rewritten as:

$(d p / d W)_{S=S} *=G(T N) h\left(P^{*}, S^{*}\right) \frac{L}{X}\left[1+n-n F_{L} P^{*} / W\right]$.

Equation ( 9 ) then becomes:

$\left(g^{\prime}\right)(d p / d W)_{S=S *}=r G(T N)$.

The empirical counterpart to the equilibrium condition ( 7 ) is thus:

$$
P=\frac{-\gamma}{1-\delta} G(T N)\left[W-W^{x}\right]+1
$$

The estimating equation linearizes $(10)$, assumes that there are some variables 2 that determine $\delta$ care indicators of the degree of workers' relative risk aversion) and writes wages in logarithms. 5 Because workers' initial choices among firms were based on the expected risk of displacement, the reservation wage too will be positively related to the probability of displacement and should be included in the equation. $W^{r}$ is therefore added to (10) to reflect the compensating wage differential that should exist between the exante risk of plant closing and the returns to otherwise identical workers. The basic estimating equation is thus:

(10') $p=a_{0}-a_{1}\left[1 n W-1 n W^{r}\right]+a_{2} 1 n W^{r}-a_{3} G(T N)+a_{4} H(Z)$.

If the hypotheses put for th here are correct: 1) The term in [1nW - Inwry will have an inverse relation to $p$. Shocks to the distribution of prices will cause the internal labor market to trace out a locus of temporary equilibria like that shown in Figure 1.2) A quadratic in tenure will have alternating negative and positive coefficients. This results from the extra value added to the firm's net worth by the firm-specific human capital that is indicated 
by greater worker terure, an increment whose value diminishes with additional tenure. 3 ) Any variable in 2 that indicates areater relative risk aversion by workers will have a negative effect on $p$.

The data used to estimate $\left.110^{\circ}\right)$ come from the Panel study of Income Dynamics. The file of household heads was searched to find all those who reported that they had left their previous jobs some time in 1977-81 because the plant shut down (displaced workers) or because they were laid off permanently (laid-off workers). The PSID is unique among major data sets in distinguishing between these two types of involuntary job-leavers, a distinction that is crucial in estimating the model derived above. The restriction that data on all the required variables be available left samples of 114 displaced workers and 203 permanent layoffs. Data on 2533 household heads who were not displaced or permanently laid off during this five-year period were also added to the working data file.

This file was selected to increase the number of households who experienced the uncommon event--job displacement--above the population percentage. While the choice-based sampling procedure does reduce the randomness associated with the sample statistics calculated on the displaced and laid-off subsamples separately, it also results in probit estimation of (10') yielding a biased constant term and biased standard errors. Accordingly, I estimate $\left(10^{\circ}\right)$ using the we ighted exagenous sampling maximum likelihood estimator (WESML) of Manski-Lerman $(1977$ ). The weight on each observation is the ratio of its population percentage based on data for all household heads in the PSID) to its frequency in the sample. Given the sampling scheme I have used, the WESML estimates of (10\%) weight the abservations on displaced and laid-off workers less heavily than those a. non-separated workers. 
For each involuntarily separated worker denote by $T$ the year the person was reported as separated. Then $\mathrm{P}_{T}$ is a dichotomous variable indicating whether or not the worker was displaced (laid-off in some of the estimates) between years $T-1$ and $T$. The data are available both for hourly-paid workers and for salaried workers. The wage rate immediately before involuntary separation, denoted by $W_{T-1}$, is used to represent the worker's wage. To represent $w^{r}$ I note that even the random components of workers' wages on their most recent jobs affect their search behavior (Kiefer-Neumann, 1979); Feldstein-Poterba, 1984). That being the case, $w^{r}$ is measured as the worker's wage at time $T-2$, minus an adjustment equal to the wage effect of the worker's tenure with the firm. 6 Years of tenure with the employer measure TN. Because data on wages at $T-1$ and $T-2$ are required, the sample is restricted to workers who have been with the firm for at least one year at the time of displacement. Since the underlying theory is based on contracting, and since workers with less than one year of tenure are less likely to have established a contractual relationship with the employer, the necessity of restricting the sample in order to observe two years' wages causes no problems.

It is difficult to determine what variables to include in the vector $z$, as there has been little empirical work establishing the correlates of risk aversion in the labor market. Partly following Thaler-Rosen (1975) I include years of education (EDUC), and dummy variables for union membership (UNION) and race (BLACK) in 2 . Presumably, ignoring issues of selection, more schooling reduces risk aversion, while membership in a union or in a minority group increases it. Clearly, however, these are merely expectations based on casual observation and are not in any sense derivable.

Data on industry-specific output shocks are auailable, but do not belong in $\left(10^{\prime}\right)$ : Such shocks are what move workers and firms along the equilibrium 
locus EE'; they do not shift the locus. These data were collected, though not included in the probits, to examine whether negative shocks are associated with leftward movements along the locus. The particular data used to measure lagged percentage changes in output between $T-1$ and $T-2$, and $T-2$ and $T-3$, $\Delta Y_{T-1}$ and $d Y_{T-2}$, are series on output in the two-digit industry in which the household head worked at time T-1.

\section{Estimates of the Locus of Equilibria}

Before examining the shape of the locus EE', let us compare the characteristics of displaced workers to those of other workers. Table 1 shows statistics describing the subsamples, with the data weighted to reflect the fractions of all household heads in each category during the five years, 1977-1981. As Table 1 clearly indicates, displaced workers on average received significantly smaller wage increases the year before their plants closed than did other workers. This simple difference in means suggests that the equilibrium locus does have the expected negative slope.

Aside from these differences, however, the two groups differ in only three respects: 1) The displaced workers suffer a sharp decline in weeks worked during the calendar year before they report having been displaced. This decline is not accompanied by any measured decline in the intensity of work: Hours stay roughly constant for this group of workers. The decline may thus be an artifact of the timing of interviews, insofar as some workers were displaced well before the end of the previous year and reported reduced weeks at work during that year. In any case, it is noteworthy that their weeks worked were essentially the same as those of other workers two years before displacement. 2) The average educational attainment of displaced workers is significantly below that of other workers. 3) output changes in the 
Table 1. Means and Their Standard Errors

\begin{tabular}{|c|c|c|c|}
\hline & $\begin{array}{c}\text { (1) } \\
\text { Displaced }\end{array}$ & $\begin{array}{l}\quad(2) \\
\text { Not Separated } \\
\text { Involuntarily }\end{array}$ & $\begin{array}{c}\text { (3) } \\
\text { Laid off }\end{array}$ \\
\hline $\operatorname{Ln}\left(W_{T-1}\right)-\ln \left(W_{T-2}^{r}\right)$ & $\begin{array}{l}.081 \\
(.03)\end{array}$ & $\begin{array}{l}.150 \\
(.01)\end{array}$ & $\begin{array}{l}.128 \\
(.02)\end{array}$ \\
\hline $\mathrm{WKS}_{\mathrm{T}-1}$ & $\begin{array}{l}42.37 \\
(1.14)\end{array}$ & $\begin{array}{l}46.87 \\
(.25)\end{array}$ & $\begin{array}{l}40.68 \\
(1.16)\end{array}$ \\
\hline $\mathrm{WKS}_{\mathrm{T}-2}$ & $\begin{array}{l}47.11 \\
(.77)\end{array}$ & $\begin{array}{l}47.12 \\
(.24)\end{array}$ & $\begin{array}{l}49.05 \\
(.94)\end{array}$ \\
\hline $\mathrm{HRS}_{\mathrm{T}-1}$ & $\begin{array}{l}43.98 \\
(1.05)\end{array}$ & $\begin{array}{l}42.75 \\
(.27)\end{array}$ & $\begin{array}{l}43.42 \\
(.85)\end{array}$ \\
\hline $\mathrm{HRS}_{\mathrm{T}-2}$ & $\begin{array}{l}43.72 \\
(.92)\end{array}$ & $\begin{array}{l}42.89 \\
(.27)\end{array}$ & $\begin{array}{l}44.49 \\
(.47)\end{array}$ \\
\hline $\mathrm{TN}_{\mathrm{T}-1}$ & $\begin{array}{l}7.84 \\
(.82)\end{array}$ & $\begin{array}{l}8.02 \\
(.16)\end{array}$ & $\begin{array}{l}4.59 \\
(.29)\end{array}$ \\
\hline UNION & $\begin{array}{l}.291 \\
(.04)\end{array}$ & $\begin{array}{l}.331 \\
(.01)\end{array}$ & $\begin{array}{l}.332 \\
(.03)\end{array}$ \\
\hline BLACK & $\begin{array}{l}.367 \\
(.05)\end{array}$ & $\begin{array}{l}.320 \\
(.01)\end{array}$ & $\begin{array}{l}.589 \\
(.04)\end{array}$ \\
\hline EDUC & $\begin{array}{l}11.03 \\
(.30)\end{array}$ & $\begin{array}{l}11.96 \\
(.08)\end{array}$ & $\begin{array}{l}11.63 \\
(.27)\end{array}$ \\
\hline$\Delta \mathrm{Y}_{\mathrm{T}-1}$ & $\begin{array}{l}3.43 \\
(.59)\end{array}$ & $\begin{array}{l}4.34 \\
(.11)\end{array}$ & $\begin{array}{l}2.48 \\
(.50)\end{array}$ \\
\hline$\Delta \mathrm{Y}_{\mathrm{T}-2}$ & $\begin{array}{l}2.55 \\
(.50)\end{array}$ & $\begin{array}{l}3.78 \\
(.13)\end{array}$ & $\begin{array}{l}3.00 \\
(.45)\end{array}$ \\
\hline $\ln W_{T-2}^{r}$ & $\begin{array}{l}6.16 \\
(.10)\end{array}$ & $\begin{array}{l}6.23 \\
(.03)\end{array}$ & $\begin{array}{l}6.43 \\
(.11)\end{array}$ \\
\hline Manufacturing & $\begin{array}{l}.418 \\
(.05)\end{array}$ & $\begin{array}{l}.349 \\
(.01)\end{array}$ & $\begin{array}{l}.375 \\
(.03)\end{array}$ \\
\hline Number in Sample & 114 & 2522 & 203 \\
\hline
\end{tabular}


industries in which dieplaced workers were employed were below those in the industries where the sample of non-separated workers held jobs, implyirg that shocks to output did move workers and firms leftwardalong an EE'locus. In all other respects, particularly in years of tenure with the employer, workers whose plants close are not significantly different from those who are not separated involuntarily. 7

It is interesting to note that displaced workers as a group differ in several important respects from workers who are laid-off permanently con whom data are shown in the third column of Table 1). Unlike displaced workers, employees who were permanently laid off received wage increases during the year before layoff that did not differ significantly from those received by other workers. Also, and not surprisingly, given the prevalence of seniority rules even in nonunion workplaces (see Abrahami-Medoff, 1984), the average tenure of permanent layoffs is significantly below that of other workers, including displaced workers. Also, laid-off workers had significantly higher wage rates than non-separated workers. These considerations corroborate our expectation in section II that the process that induces permanent layoffe is basically different from that which engenders the wage-employment outcomes observed before and during plant closings.

Equation $\left(10^{\circ}\right)$ is estimated over the 2636 displaced and non-separated workers using weighted probit (WESML) analysis, with the results for the complete specification, and for selected modifications of io's, presented for displaced workers in Table 2 . The standard errors that are used to compute t-statistics were calculated using the matrices suggested by Manski-Lerman (1977). The simple bivariate probit of the probability of displacement on the previous period's percentage wage change shows that shocks that increase the probability of displacement also significantly reduce the wage increase. The 
Table 2. Probit Analysis of the Probability of Displacement $(\mathrm{N}=2636)$

\begin{tabular}{|c|c|c|c|c|}
\hline & (1) & (2) & (3) & (4) \\
\hline Constant & $\begin{array}{l}-1.916 \\
(-26.36)\end{array}$ & $\begin{array}{l}-1.833 \\
(-15.02)\end{array}$ & $\begin{array}{l}-.528 \\
(-.69)\end{array}$ & $\begin{array}{l}-.744 \\
(-.97)\end{array}$ \\
\hline $\ln \left(\mathrm{W}_{\mathrm{T}-1}\right)-\ln \left(\mathrm{W}_{\mathrm{T}-2}^{\mathrm{T}}\right)$ & $\begin{array}{c}-.587 \\
(-1.74)\end{array}$ & $\begin{array}{l}-.579 \\
(-3.85)\end{array}$ & $\begin{array}{c}-.701 \\
(-3.58)\end{array}$ & $\begin{array}{c}-.629 \\
(-5.56)\end{array}$ \\
\hline $\mathrm{TN}_{\mathrm{T}-1}$ & & $\begin{array}{l}-.0246 \\
(-1.04)\end{array}$ & $\begin{array}{l}-.0230 \\
(-0.96)\end{array}$ & $\begin{array}{l}-.0289 \\
(-1.20)\end{array}$ \\
\hline $\mathrm{TN}_{\mathrm{T}-1}^{2}$ & & $\begin{array}{l}.00088 \\
(1.11)\end{array}$ & $\begin{array}{l}.00088 \\
(1.08)\end{array}$ & $\begin{array}{r}.00094 \\
(1.17)\end{array}$ \\
\hline $\ln \left(W_{T-2}^{r}\right)$ & & & $\begin{array}{l}-.210 \\
(-1.73)\end{array}$ & $\begin{array}{l}-.0834 \\
(-1.19)\end{array}$ \\
\hline BLACK & & & & $\begin{array}{r}-.0265 \\
(-.19)\end{array}$ \\
\hline Years of School & & & & $\begin{array}{l}-.0437 \\
(-1.94)\end{array}$ \\
\hline UNION & & & & $\begin{array}{c}(-.0768 \\
(-.58)\end{array}$ \\
\hline \multicolumn{5}{|l|}{ Manufacturing } \\
\hline $\ln L$ & -465.06 & -463.52 & -459.79 & -456.77 \\
\hline
\end{tabular}


slope of this relation 'ip is fairly sma11, -.034: Each one-percent arop in real wage growth is associated with an increase in the probability of the plant closing of .00034. Since the mean probability of plant closing is .023, a one-percent wage decrease is associated with a 1.5 percent increase in the probability the plant closes. This suggests that, while the absolute effect on the probability of closing is small, so liat most of the impact of a shock is taken up by reductions in wage growth, the relative effect is fairly substantial.

When quadratic terms in tenure are added to the basic bivariate probit, the results (in column (2)) provide some confirmation of the idea that the firm shares ownership in an asset that adds more to outpu: than to costs. There is a U-shaped response of the probability that the worker will be displaced (that a plant closes) to increases in workers tenure. Since the theory of investment in on-the-job training suggests that the stock of this type of training increases at a decreasing rate with tenure, and since 1 viewed firm-specific training as augmenting the value of raw labor, I expected these effects on the probability of displacement. At the mean of tenure in the sample of 2636 displaced and non-separated workers, the marginal effect of a year of tenure on the probability the plant closes is -.00076 . Though its absolute effect is quite smali, relative to the mean probability of displacement additional firm-specific experience substantially reduces the probability that the firm will close. The embodiment of additional firm-specific human capital in its work force partly insulates the firm from product-market shocks.

Although the results on tenure are not very significant, it is worth thinking about what they imply about the nature of relationships between firms and workers. It is impossible to infer from the wage-tenure relationships in 
standard earnings equations whether the results reflect firm-specific investment, learning without investment, or payment by seniority to provide incentives not to shirk. While the admittedly weak results on the effects of tenure in Table 2 do not permit one to distinguish between the first two explanations, it is difficult to concoct an explanation for them based on incentives to avoid shirking. Indeed, since the difference between wages and productivity rises with tenure in models of shirking, the value of the firm will fall as average tenure increases, other things equal. This means that we would abserve firms with a work force with greater tenure being more liable to close when faced with a negative demand shock. Obuiously, one piece of empirical work hardly provides a definitive test of two hypotheses that have hitherto been observationally indistinguishable. However, the results do point the way toward further tests, and do indicate the tendency of some preliminary evidence.

The estimates in columns (3) and (4) reflect the inclusion of $1 \mathrm{nw}^{\mathrm{r}}$ and of terms designed to capture proxies for workers' preferences toward risk. The results in column (4) contain the full specification in equation (10). The derivation in section III indicated that characteristics that might be expected to proxy a higher degree of relative risk aversion will have a negative effect on the probability of displacement, other things equal. Only one of the three estimated parameters is significantly different from zero (and its sign is unexpected), but the other two, those on union status and race, have the expected negative signs. Perhaps the best conclusion from these disappointing results is that it is difficult to find readily available empirical proxies for attitudes toward risk. Unexplained heterogeneity is all one can identify as causing differences among workers in how they respond to shocks to product demand among otherwise identical firms. 
Contrary to the derivation, there is a significant negative effect of a worker's market wage rate on the probability that the plant will close. Apparently, as is common in the literature on compensating wage differentials (e.9., Brown, 1980), the trade-off between security and the wage rate is more than offset by the income effect of higher earnings on the demand for security. From this point of view it is not surprising, since the variables I have modelled as reflecting tastes can also be viewed as reflecting market opportunities, that the negative effect of 1 nWr becomes much smaller and less significant once the vector of three variables is added.?

Summarizing the results as a whole, a number of the factors discussed in Section II do have the expected effects on the probability of a plant closing. None of the effects is very large in absolute terms. Relative to the underlying chance that a worker will be displaced, though, they are quite substantial.

That the predictions of the derivations of Section II apply only when one can assume that there is an identifiable locus of equilibria between workers" preferences and firms' probabilistic shut-down frontiers is suggested by an examination of the same weighted probits estimated for the probability of permanent layoff (shown in Table 3). The sample consists of the 2031 aid-off workers and the same group of non-separated workers used in the estimates shown in Table 2. As suggested by the means in Table 1, the relationship between the probability of permanent layoff and wage change in the previous year is much weaker than in the sample of displaced and other workers. Indeed, while there is a negative relationship between 1 nW - $1 \mathrm{nW}^{\mathrm{r}}$ and the probability of permanent layoff, it is never significant at conventional levels.

In Hamermesh (1984) I demonstrated a substantial flattening of 
Table 3. Probit Analysis of the Probability of Permanent Layoff $(\mathrm{N}=2725)$

\begin{tabular}{|c|c|c|c|c|}
\hline & (1) & (2) & (3) & (4) \\
\hline Constant & $\begin{array}{c}-1.706 \\
(-26.61)\end{array}$ & $\begin{array}{c}-1.455 \\
(-15.31)\end{array}$ & $\begin{array}{l}.424 \\
(.69)\end{array}$ & $\begin{array}{l}-.642 \\
(-1.49)\end{array}$ \\
\hline $\ln \left(\mathrm{w}_{\mathrm{T}-1}\right)-\ln \left(\mathrm{w}_{\mathrm{T}-2}\right)$ & $\begin{array}{c}-.265 \\
(-1.02)\end{array}$ & $\begin{array}{l}-.215 \\
(-.87)\end{array}$ & $\begin{array}{l}-.340 \\
(-1.30)\end{array}$ & $\begin{array}{l}-.213 \\
(-.77)\end{array}$ \\
\hline $\mathrm{TN}_{\mathrm{T}-1}$ & & $\begin{array}{l}-.0340 \\
(-1.95)\end{array}$ & $\begin{array}{l}-.0306 \\
(-1.45)\end{array}$ & $\begin{array}{c}-.0453 \\
(-1.85)\end{array}$ \\
\hline $\mathrm{TN}_{\mathrm{T}-1}^{2}$ & & $\begin{array}{r}-.00095 \\
(-1.86)\end{array}$ & $\begin{array}{r}-.00102 \\
(-1.61)\end{array}$ & $\begin{array}{c}-.00071 \\
(-.99)\end{array}$ \\
\hline $\ln \left(w_{T-2}^{r}\right)$ & & & $\begin{array}{l}-.305 \\
(-3.02)\end{array}$ & $\begin{array}{l}-.0562 \\
(-.80)\end{array}$ \\
\hline BLACK & & & & $\left(\begin{array}{c}320 \\
(2.95)\end{array}\right.$ \\
\hline Years of School & & & & $\begin{array}{l}-.0498 \\
(-2.88)\end{array}$ \\
\hline UNION & & & & $\begin{array}{l}.0656 \\
(.70)\end{array}$ \\
\hline \multicolumn{5}{|l|}{ Manufac turing } \\
\hline $\ln \mathrm{L}$ & -721.24 & -689.77 & -678.24 & -660.69 \\
\hline
\end{tabular}

a The effect of a unit increase in a particular variable on $p$ is its coefficient estimate times .0871. 
wage-tenure profiles among workers who would later experience permanent layoff, but no flattening among those whose plants would later close. I interpreted this to mean that the probability of permanent layoff becomes clear to workers much earlier before the event occurs than does the probability of displacement. Here one can interpret the difference in the results between Tables 2 and 3 as reflecting the unwillingness of workers in plants where wage structures exist to accept wage cuts that at best will reduce the probability of layoff for a few (junior) workers, but will surely reduce the wages received by all workers. On the other hand, workers seeing a shock that increases the probability that the entire plant will close are willing to accept a general reduction in wage growth that reduces in part the increased risk that they will all lose their jobs.

The supporting evidence provided by the coefficients on the terms in TN in the probits for displacement is not observed in these probits. Increased tenure does reduce the probability of permanent layoff; but there is no quadratic effect of opposite sign. ${ }^{10}$ As in the weighted probits describing displacement, the union status variable is insignificant; the dummy variable for race, and the measure of schooling attainment too, have coefficients that are significantly different from zero. However, these variables affect the probability of permanent layoff in directions that differ in all three cases from what we predicted, but that support what evidence from other sets of data leads one to expect: There is a higher probability of permanent layoff with union status, among blacks and with lower educational attainment. 11

\section{U. Applications of the Estimates}

The probit coefficients in Table 2 can be used in conjunction with the derivation of (10) to examine two aspects of labor-market behavior. The 
general idea is to note that each point along the estimated probit represents an equilibrium of an indifference curve and a probabilistic shut-down frontier and, under specific assumptions about the nature of these maps, infer something more about their shapes and locations. The inferences rest on approximations that hold only locally around the locus of equilibria; but in that region the assumptions, together with the notion of a probabilistic shut-down frontier, Enable us to analyze labor-market behavior in ways not heretofore possible.

\section{A. Labor-Demand Elasticities}

Throughout I assume that workers' indifference maps are homothetic around the point of equilibrium. I assume that the map of probabilistic shut-down frontiers is homothetic too, though I relax that assumption in some of the calculations. The approach can be used to infer the typical firm's "demand elasticity" for an individual worker. With both maps homothetic the slope of the shut-down frontier at a point on the equilibrium locus is the inverse of the slope of that locus. The resulting measure is not a standard total labor-demand elasticity, since it does not relate employment levels to wage levels. Rather, it is an analogue that can be made comparable to standard estimates if we assume that the rate of change in the individual worker's probability of employment induced by higher wages equals the expected percentage decline in the typical firm's demand for workers.

At the mean values of all the variables a fraction po all workers will be displaced in each time period if demand conditions in the typical firm are indexed along the particular shut-down frontier $5 * 5 *$. An increase in lnw will raise this fraction, so that in percentage terms the effect of a one-percent increase in wages is: 
$p(s p / s 1 n W) s=5 *$

Since the change in lnw is just the change along the horizontal axis in a version of Figure 1 that has $w=\ln w-\ln W^{\Gamma}$ on the horizontal axis, we can measure the slope of $5 * 5 * a s$ the inverse of the slope of the EE locus.

If the probabilistic shut-down frontiers do not exhitit parallel shifts as demand shocks occur, the linear approximation to their slopes at the locus of equilibria will be incorrect. Consider Figure $2 a$, which shows $\overline{C D^{*}} / \overline{A C}$, the slope of the equilibrium locus EE at a particular point A. The frontier tangent to the indifference curve at $A$ is $5 * S *$. As the particular example is drawn, the inverse of the slope of $E E^{\prime}$ at $A$ overstates the slope of $S * 5 *$, for $E^{\prime}$ is becoming flatter as $w$ increases. Thus the slope of $s * S *, \overline{B C} / \overline{A C}$, should be calculated as $\overline{A C} / \overline{C D}$ rather than as $\overline{A C} / \overline{C D}$. To accomplish this I use a second-order approximation to $\mathrm{EE}^{\prime}$ and infer that:

$\frac{\overline{B C}}{\overline{A C}}=[\partial p / \partial W]^{-1}\left[1-\frac{\partial^{2} p / \partial W^{2}}{\partial p / \partial W}\right]$

This modification corrects the estimate of the slope of $5 *$ for the changing slope of EE', a change that in turn is assumed to be produced by the possible nonhomotheticity of the family of probabilistic shut-down frontiers.12

The first row of Table 4 shows the first-and second-order approximations to the slope of the probabilistic shut-down frontier at the sample means along the equilibrium locus of combinations of $p$ and $w$. The calculations are based on the estimat a ighted probits in column (4) of Table 2. Each figure shows the percentage increase in the probability of the worker losing a job because of a plant closing in response to a one-percent increase in the wage rate, holding expected product-market conditions constant.

The estimates are well in line, or, in the case of the first-order approximation, perhaps slightly higher than those produced in studies of 


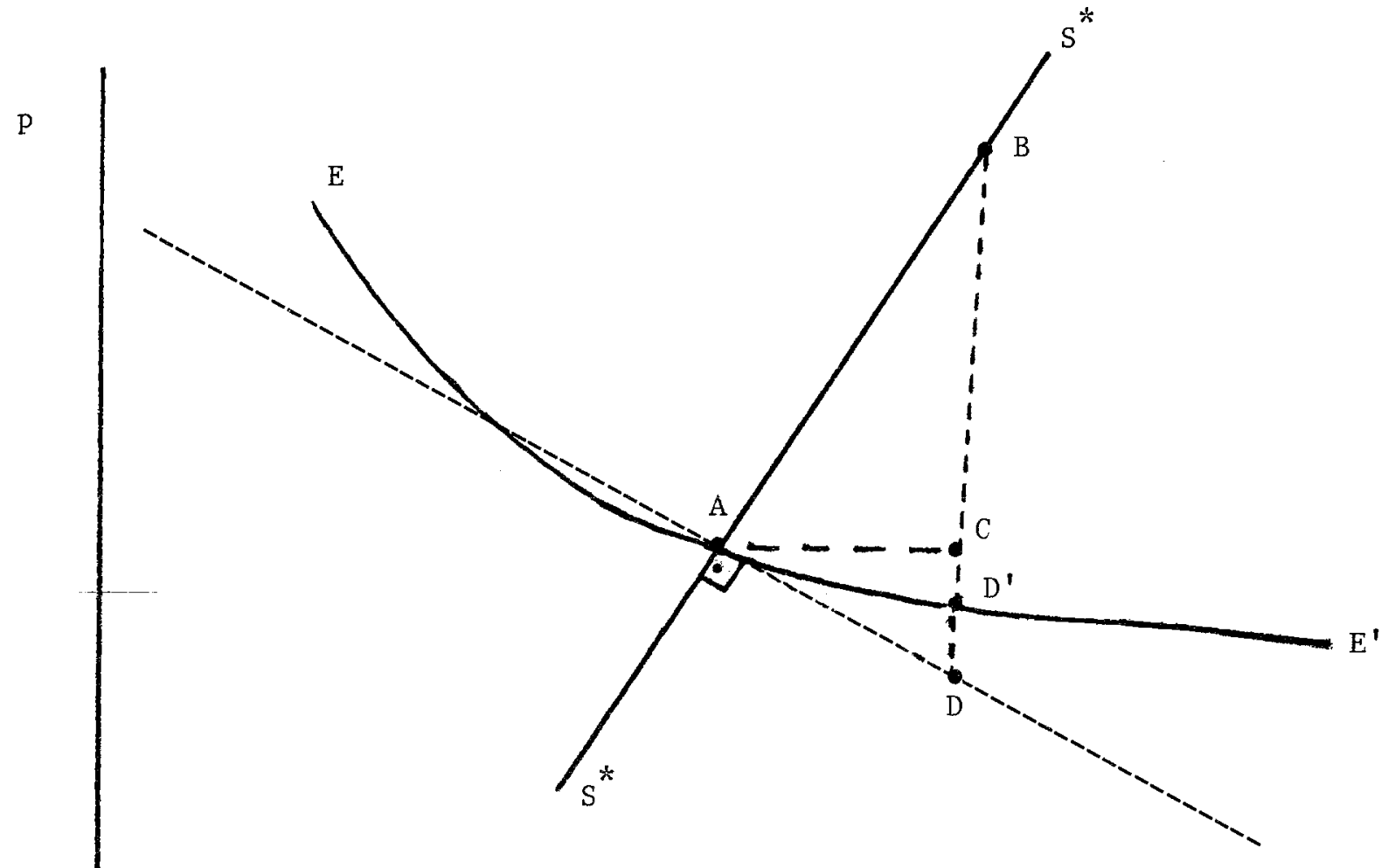

Figure 2a. Calculating the Slope of $\mathrm{S}^{*}$ 
Table 4. Estimates of Parameters Derived from Table 2, Column (4)

First-order Approximation
Second-Order Approximation

\begin{tabular}{lcc}
\hline \hline a. Labor-demand Elasticity & -.86 & -.37 \\
b. Required wage concession, in percent & -34.93 & -34.97
\end{tabular}


aggregated data for industries or entire economies. CSee Hamermesh, 1986, for. : iscussion of these estimates and some of the problems with them.) since these elasticities are based entirely on micro data, they are likely to be larger than standard estimates: They reflect all changes in employment induced by wage changes in a small unit, instead of netting out employment increases in other firms and among other demographic groups that occur in an industry or economy when a particular wage increases. That they are not much larger than comaly-cited estimates indicates that the gross-net distinction is not particularly vital. This suggests that using aggregate estimates to infer the likely impacts of proposed changes in taxes on or subsidies to wages will not create very large errors.

\section{B. Response to Product-Market Shocks}

The estimates of Section IU can also be used to infer the size of the wage concession required to keep a plant's probability of closing constant when a negative demand shock occurs. In light of the recent interest in wage concessions (see Mitchel1, 1982), these estimates should indicate the extent of the concessions needed to prevent employment declines when product market demand drops, and the willingress of workers to offer these concessions. As such, they should be a more general set of evidence on the issue than that provided by an examination of a few collective bargaining situations. More important, they link wage concessions to employment protection, which is, after all, their ostensible purpose.

Consider the schematic in Figure $2 b$, in which I assume a negative demand shock has shifted the probabilistic shut-down frontier from $5 * 5 *$ to $5 * 5 *$ *. A wage concession of $\overline{A^{\prime} D}$ will be required if the probability of plant closing is not to rise above what it was at $A^{\prime}$. It will not be optimal for workers to 


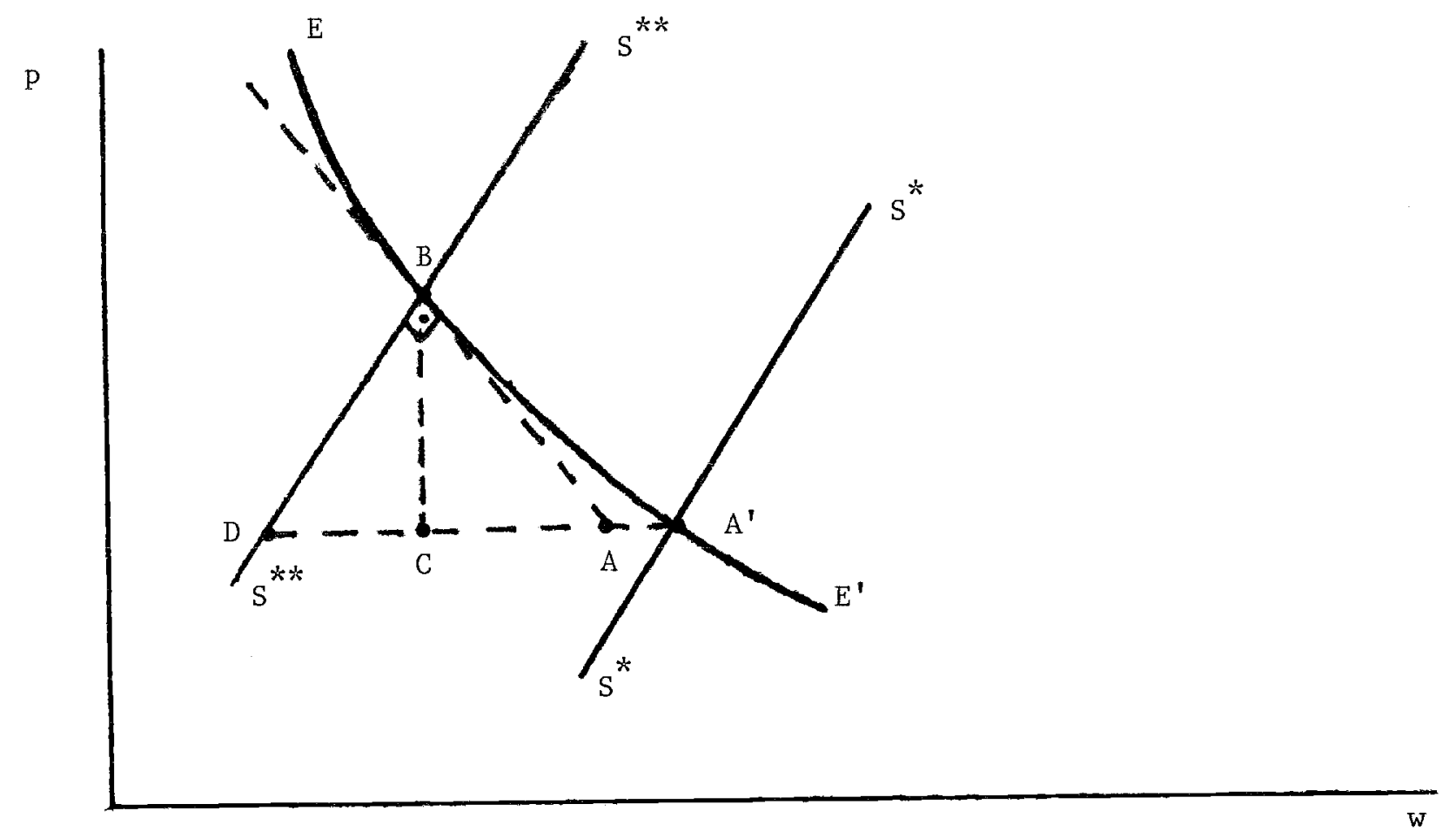

Figure 2b. Calculating Required Wage Concessions 
offer this large a concession, as $D$ is not on the locus of equilibria. I calculate it in order to indicate what is needed, not what will occur. Assume one knows the size of the increase in the probability of closing, $\overline{B C}$, that accompanies a move from $A^{\prime}$ to $B$. If both the equilibrium locus EE and the new zero-profit frontier $S * * S_{*} *$ were 1 inear, l could calculate the required wage decrease $\overline{A^{\prime} D}=\overline{A^{\prime} C}+\overline{C D}$ as $\left\{[\varepsilon p / \varepsilon w]^{-1}+\delta_{p} / \varepsilon_{w}\right\}$ times the change in the probability of displacement, BC, that would have otherwise occurred. While I cannot adjust for the possible nonlinearity of $S * S^{* *}$, I can obtain a better measure of the true distance $\overline{C D}$ by making the same second-order approximation used before. In particular, the corrected decrease required to keep the probability of displacement from rising by an amount $\overline{B C}$ is:

$$
\overline{A^{\prime} D}=\overline{A^{\prime} C}+\overline{C D}=\left\{\left(\frac{\partial p}{\partial W}\right)^{-1}+\partial p / \partial W\left[1-\frac{\partial^{2} p / \partial W^{2}}{\partial p / \partial W}\right]\right\} \overline{B C} \text {. }
$$

Assuming that $p$ would rise by .01 in response to a particular shock $(B C=.01)$, the estimates of the percentage change in wages required to return the probability of displacement to its pre-shock level are shown in the second row of Table 4. The flatness of the equilibrium locus guarantees that the required wage cuts are quite large. Decreases of over 30 percent are required to prevent the probability of plant closing from rising by one percentage point when a negative shock occurs. Cof course, a one percentage-point rise in this probability represents a 41.8 percent increase in the risk that the plant closes.) The behavior implicit in the estimated equilibrium locus perhaps explains why workers are loath to make wage concessions to "save jobs:" The required concessions are so large relative to the effect on the probability of retaining employment that even risk-averse workers would rather take the increased probability of the plant closing than accept the certainty of a substantial cut in pay. Given the shapes of utility functions and probabilistic shut-down frontiers, it is socially optimal for workers to bear 
this increased risk rather than take larger pay cuts. 13

Pay cuts of the magnitude needed to hold constant the probability of plant closing are not accepted because uncertainty about this probability makes their acceptance an inferior solution from the worker's point of view. However, the estimates in Table 2 clearly show that some wage cuts are accepted in response to negative product-market shocks. This stands in sharp contrast to the suggestion of Lawrence-Lawrence (1985) that, as part of bargaining in the face of declining demand, unions and firms will agree to above-average wage increases. It may be true that such increases are observed in isolated cases of decinining product demand; our results show, though, that they do not describe the responses of most firms and their employees.

\section{vi. Conclusions}

In this study I have developed a contracting approach to examining plant closings. These are viewed as probabilistic events whose likelihood is exogenously changed by variations in product demand, and is also affected by workers' attitudes toward risk and by firms' technology. The exogenous shocks interact with the taste and technology parameters to produce a locus of equilibrium combinations of wage changes and probabilities of plant closings. Because workers' tenure represents an asset that produces quasi-rents for the firm (as well as quasi-rents for workers in the form of higher wages), changes in workers tenure affect the relation between wage changes and the probability of plant closing when a shock occurs.

This approach is examined using data from the Panel study of Income Dynamics, the only available longitudinal data set that distinguishes people who have lost their jobs due to plant closings from those separated involuntarily for other reasons. The estimates based on these data show the 
expected negative relation between wage changes and the probability of plant closing. Additional years of worker tenure are shown to reduce the probability of plant closing at a fixed rate of wage changes; and the marginal reduction diminishes as tenure rises, implying the same quadratic snape to the relationship between the quantity of firm-specific human capital and its empirical proxy, tenure with the firm, as is implied by estimated wage-tenure relations.

The results are used to calculate an analogue to a firm's labor-demand elasticity. The estimates of the elasticity range from . 35 to 9,9 roughly consistent with results obtained by others using aggregated data. The results on the determinants of the probability of plant closing also allow one to infer that negative demand shocks would have to be met with wage increases far below average if increases in the probability of shut-down are to be avoided. This suggests one reason for worker ${ }^{\prime}$ resistance to wage concessions in the face of what often seems like a riskier labor market: Why accept the certainty of a substantial wage cut in return for only a small reduction in the risk that the plant will close?

If nothing else the estimates demonstrate clearly the simple empirical fact that average wages grow less rapidly in plarits that will soon close. I use these results to support an underlying model of internal labor markets in which firms and the workers tied to them respond to exogenous shocks by accepting wage changes and a new probability of plant shut-down. To refine the approach and link the estimates still more closely to the underlying model, one reeds data that allow the inference of specific forms of the underlying utility functions and probabilistic shut-down frontiers, thus obviating the need to make the assumptions required here. Data linking firm. and workers are needed to permit better estimates to be drawn. Longitudinal 
data are also needed on larger samples of displaced workers: while the

estimates provided here are generally significant, they are not always so, a failing that may result from the small sample of displaced workers in the total PSID. 


\section{REFERENCES}

Katharine Abraham and James Medoff, "Length of Service and Layoffs in Union and Nonunion Work Groups," Industrial and Labor Relations Review, 38 $(1984), 87-97$.

Costas Azariadis, "Implicit Contracts and Underemployment Equilibria," Journal of Political Economy, $83(1975), 1183-1202$.

Martin Baily, "Wages and Unemployment under Uncertain Demand, "Review of Economic Studies, $41(1974), 37-50$.

Francine Blau and Lawrence Kahn, "Causes and Consequences of Layoffs," Economic Inquiry, $19(1981), 270-296$.

Charles Brown, "Equalizing Differences in the Labor Market," Quarterly Journal of Economics, $94(1980), 113-134$.

Congressional Budget office, Dislocated Workers: Issues and Federal Options. Washington, Government Printing office, 1982.

Martin Feldstein and James Poterba, "Unemployment Insurance and Reseruation Wages," Journal of Public Economics, $23(1984), 141-167$.

Daniel Hamermesh, "The Costs of Worker Displacement," Working Paper No. 1t95, National Bureau of Economic Research, 1984.

- "The Demand for Labor in the Long Run," in Orley Ashenfelter and Richard Layard, Handbook of Labor Economics. Amsterdam, North-Holl and Press, 1986.

Nicholas Kiefer and George Neumann, "An Empirical Job Search Model, wi th a Test of the Constant-Reservation-Wage Hypothesis," Journal of Folitical Economy, $87(1979), 89-107$.

Colin Lawrence and Robert Lawrence, Manufacturing Wage Dispersion: An End Game Interpretation," Brookings Papers on Economic Activity, (1985), 
$47-106$

Edward Lazear, "Why Is There Mandatory Retirement?" Journal of Political

Economy, $87(1979), 1261-1284$.

Charles Manski and Steven Lerman, "The Estimation of Choice Probabilities from Choice-Based Samples," Econometrica, 45(1977), 1977-1988.

Jacob Mincer and Boyan Jovanovic, "Labor Mobility and Wages," in Sherwin Rosen, ed. Studies in Labor Markets. Chicago, University of Chicago Press, 1981

Daniel Mitchell, "Recent Union Contract Concessions," Brookings Papers on Economic Activity, (1982), 165-201.

John Raisian, "Contracts, Job Experience, and Cyclical Labor Market Adjustment," Journal of Labor Economics, 1 (1983), 131-151.

Sherwin Rosen, "Implicit Contracts," Journal of Economic Literature, 23 $(1985), 1144-1175$.

Richard Thaler ari cherwin Rosen, "The Value of Saving a Life: Evidence from the Labor Market," in Nestor Terleckyj, ed. Household Production and Consumption. New York, Columbia University Press, 1975.

Randall Wright, "Unemployment Insurance and the Dynamics of Voting," Working Paper No. 340, Cornell University, 1985. 


\section{FOOTNOTES}

1. Wall Street Journal, october 13,1982 , page 1.

2. See Congressional Budget Office (1982) for a discussion of the magnitude of the plant-closing problem; Hamermesh (1984) for an analysis of its social costs, and Mitchell (1982) for a discussion of the growth of wage concessions in union contracts.

3. While this relationship has not heretofore been tested, the argument is, of course, the same as that of Rosen (1974) and has been applied to estimating the relationship between wage rates and various job-related risks.

4. Differentiating in ( 6 ), one sees that:

$d^{2} p / d u^{2}=(1-p)\left(u u^{\prime \prime}-u^{2}\right) / u^{2}<0$

under standard assumptions.

5. This transformation is made to scale the wage measure to ar "unt for the heterogeneity of general training among workers as they enter the firm.

6. The size of the adjustment is based on standard wage equations estimated over the entire sample for year $T-1$ and including the usual array of demographic variables, industry dumy variables, education, total experience and its square, and years of tenure and its square. Because the observations come from different years, wage rates are made comparable across calendar time by inflating using the growth in private nonfarm hourly earnings between the time each $\omega$ is observed and 1980 .

7. While 59 percent of displaced workers have five or fewer years tenure at time T-1, 25 percent had more than ten years' tenure with their employer at that time.

8. Only 8 percent have more than ten years tenure with their employer.

9. The results on this measure, on $\ln w-\ln \mathrm{w}^{\Gamma}$ and on the tenure variables differ only slightly when $1 n \mathrm{~h}^{\Gamma} i$ s defined as $\mathrm{inw}_{\mathrm{T}-2}$, unadjusted for differences
in tenure.

10. Though the individual terms in TN in the probit in columns $(2)-(4)$ are not highly significant, sp/ETN is significantly negative, as the existence of rules requiring layoffs by inverse seniority suggests will be the case.

11. See Blau-Kahn (1981) for evidence on layoffs using data on young men and women from the NLS.

12. The correction is equivalent to a Maclaurin-series approximation to the equilibrium locus, as David Hamermesh has pointed out.

13. One union leader noted, "But, worker concessions won't save our jobs, revive our industries or help the economy." "Tony Mazzocchi, OCAW District 8 , in Worker's Policy Froject, It's Time for Management Concessions. New York. 1983. 